\title{
FIRST MOLECULAR DETECTION OF APIS MELLIFERA FILAMENTOUS VIRUS IN HONEY BEES (APIS MELLIFERA) IN HUNGARY
}

\author{
Brigitta ZANA ${ }^{1,2^{*}}$, Lili GeIGER ${ }^{1,2}$, Anett KePNER ${ }^{3}$, Fanni FöLdEs ${ }^{1,2}$, Péter URBÁN ${ }^{2,4}$, \\ Róbert HERCZEG ${ }^{1}$, Gábor KEMENESI ${ }^{1,2}$ and Ferenc JAKAB ${ }^{1,2}$ \\ ${ }^{1}$ Virological Research Group, Szentágothai Research Centre, University of Pécs, \\ Ifjúság útja 20, H-7624 Pécs, Hungary; ${ }^{2}$ Institute of Biology, Faculty of Sciences, \\ University of Pécs, Pécs, Hungary; ${ }^{3}$ PROPHYL Ltd., Mohács, Hungary; \\ ${ }^{4}$ Microbial Biotechnology Research Group, Szentágothai Research Centre, \\ University of Pécs, Pécs, Hungary
}

(Received 29 August 2018; accepted 15 February 2019)

\begin{abstract}
Western honey bees (Apis mellifera) are important pollinators in the ecosystem and also play a crucial economic role in the honey industry. During the last decades, a continuous decay was registered in honey bee populations worldwide, including Hungary. In our study, we used metagenomic approaches and conventional PCR screening on healthy and winter mortality affected colonies from multiple sites in Hungary. The major goal was to discover presumed bee pathogens with viral metagenomic experiments and gain prevalence and distribution data by targeted PCR screening. We examined 664 honey bee samples that had been collected during winter mortality from three seemingly healthy colonies and from one colony infested heavily by the parasitic mite Varroa destructor in 2016 and 2017. The subsequent PCR screening of honey bee samples revealed the abundant presence of Apis mellifera filamentous virus (AmFV) for the first time in Central Europe. Based on phylogeny reconstruction, the newly-detected virus was found to be most closely related to a Chinese AmFV strain. More sequence data from multiple countries would be needed for studying the detailed phylogeographical patterns and worldwide spreading process of AmFV. Here we report the prevalent presence of this virus in Hungarian honey bee colonies.
\end{abstract}

Key words: Apis mellifera filamentous virus, honey bee, Apis mellifera, Hungary, Europe, pathogen

Western honey bees (Apis mellifera) are not considered the most efficient pollinators in the ecosystem, but they are widely used in agriculture as primary pollinators mainly due to their generalist nature, the way of keeping and their extensive foraging ranges, which features making them extremely suitable for pollination of expansive monocultures (NRC, 2006; McMenamin et al., 2016). Unfortunately, in the last decade, an increasing overwinter decline was observed in

\footnotetext{
"Corresponding author; E-mail: brigitta.zana@gmail.com
} 
honey bee populations mainly in the USA, in some European countries and to a lesser extent in the Middle East, Asia, and Africa. The contributing factors are still unexplored; however, a general consensus suggests several interacting factors that can co-operate, such as forage quality, pathogens, pests, climate change, pesticides, and expertise of the beekeeper (Steinhauer et al., 2014).

To date, more than 20 viruses have been identified in honey bees, of which several were proved to be pathogenic while others are suspected to cause inapparent infection or just have forage origin. Most of them are single-stranded RNA viruses mainly belonging to the Dicistroviridae and Iflaviridae families (McMenamin and Genersch, 2015). Only two DNA viruses with possible pathogenicity to honey bees have been recognised. One of them is the invertebrate iridescent virus 6 (Iridoviridae) and the other one is the yet unclassified, large, enveloped dsDNA virus, namely Apis mellifera filamentous virus (AmFV), the presence of which has been verified in Switzerland and Belgium (Clark, 1978; Ravoet et al., 2014; Gauthier et al., 2015). In case of worker honey bees, acute AmFV infection is associated with the lysis of bee tissues leading to milky-white haemolymph, and these bees often found crawling at the entrance of beehive. However, the pathogenic potential of AmFV is still questionable since the signs of acute AmFV infection are rare and no considerable colony loss had been associated with AmFV in the past (Hartmann et al., 2015).

Here we present the high prevalence of AmFV in Hungarian honey bee colonies for the first time in this region.

\section{Materials and methods}

\section{Sample collection}

Dead worker honey bees were collected randomly from four apiaries in four distinct villages during the winter of 2016-2017. Of the 664 collected honey bees, 115 specimens originated from the village Visz, which were sampled from highly decaying colonies. All other specimens were collected from apparently healthy colonies from the villages of Látrány (254 specimens), Hajós (145 specimens) and Somberek (150 specimens) (Fig. 1). All samples were stored at $-80^{\circ} \mathrm{C}$ until further laboratory processes.

\section{Nucleic acid extraction}

Each honey bee was homogenised individually and the supernatants of homogenates were pooled (133 pools, 5 specimens per pool) according to geographical origin. The nucleic acid extraction was performed from the pools of supernatants using Virus DNA/RNA Extraction Kit II (Geneaid Biotech Ltd., New Taipei City, Taiwan) according to the manufacturer's instructions. 


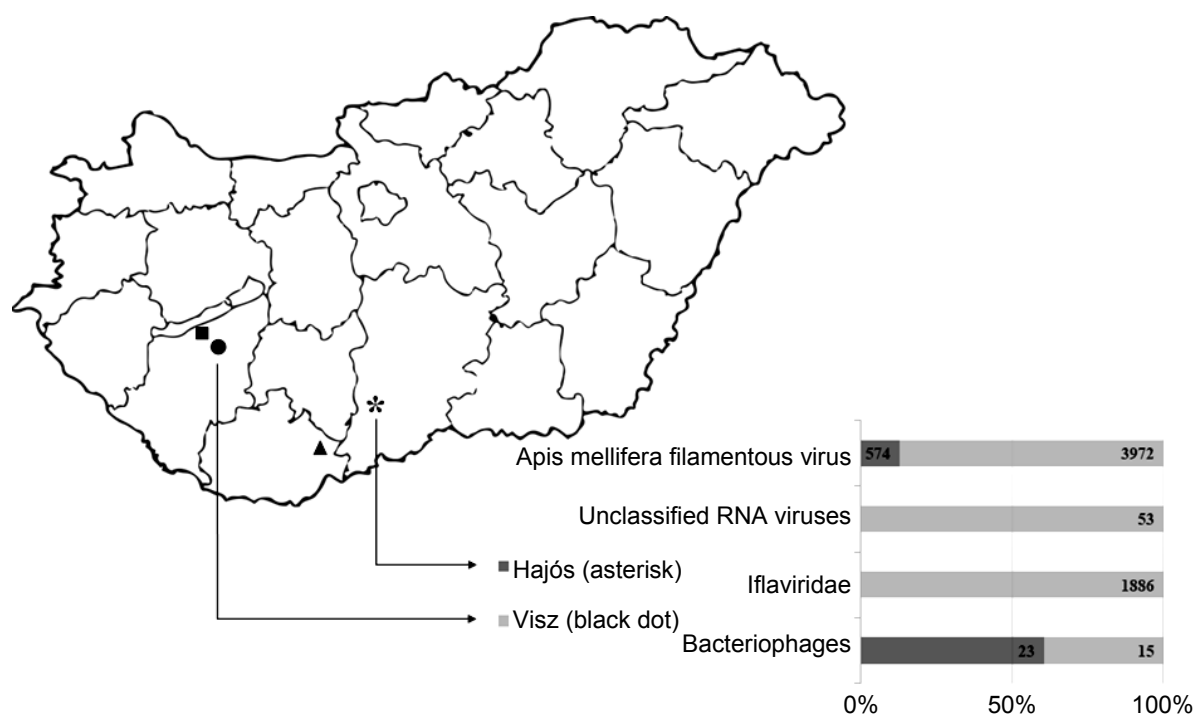

Fig. 1. Geographical locations of sampling sites within Hungary and the distribution of average read number by virus groups of samples collected in Hajós and Visz. On the blank map of Hungary, the black square ( $\bullet$ ) indicates Látrány, the black dot $(\bullet)$ indicates Visz, the black triangle $(\boldsymbol{\Delta})$ indicates Somberek and the asterisk $\left(^{*}\right)$ indicates Hajós

\section{Metagenomic survey}

Library construction for Ion PGM System (Thermo Fisher Scientific) was retrieved in case of two samples to compare their metagenomes and to reveal the presumed causative agent of the colony loss. We randomly selected a single representative homogenate from the ailing colony (Visz) and from the apparently healthy colony (Hajós), respectively. Before subjecting the samples to library preparation, all materials were exposed to a viral enrichment protocol as described by Conceição-Neto et al. (2015). Thereafter, library construction was performed by using NEBNext ${ }^{\circledR}$ Fast DNA Fragmentation \& Library Prep Set for Ion Torrent ${ }^{\mathrm{TM}}$ (New England Biolabs ${ }^{\circledR}$ Inc., Ipswich, USA) following the manufacturer's instructions. Thereafter, the cDNA libraries were loaded onto IonTorrent 316 chip and sequenced following the instructions recommended for the Ion PGM ${ }^{\mathrm{TM}}$ OT2 and Sequencing Kit.

\section{Molecular detection of AmFV and phylogenetic analysis}

Further PCRs were carried out to reveal the presence and prevalence of AmFV by the involvement of additional honey bee samples. All the 133 pools were screened with oligonucleotide primers described by Hartmann et al. (2015), using the GoTaq G2 Flexi DNA Polymerase kit (Promega, Madison, USA) according to the manufacturer's instructions. The PCR amplicons were purified us- 
ing Gel/PCR DNA Fragments Extraction Kit (Geneaid Biotech Ltd., New Taipei City, Taiwan), and were sequenced on both strands using the BigDye Terminator v1.1 Cycle Sequencing Kit (Thermo Fisher Scientific, Walthan, USA) and ABI Prism 310 Genetic Analyzer (Applied Biosystems). Basic sequence handling and verification were performed using GeneDoc v2.7 software. Multiple sequence alignment was prepared by MUSCLE online tool (Li et al., 2015). The phylogenetic tree was based on partial nucleotide sequences of the BRO-B protein coding region of AmFV sequences retrieved from the GenBank database. For the maximum-likelihood tree, the best fit nucleotide substitution model was selected based on the Bayesian information criterion as implemented in the MEGA7 software (Kumar et al., 2016). Model selection and Maximum Likelihood phylogenetic tree were constructed by MEGA7 software.

\section{Results and discussion}

The metagenomic survey of the two honey bee specimens displaying different handling background and geographic origin revealed the dominant presence of Apis mellifera filamentous virus (AmFV) in both samples, although with different read number distributions (Hajós: 574 reads of 637 viral reads; Visz: 3,972 reads of 6,020 viral reads) (Fig. 1). However, the analysis revealed a more prominent difference in the two metagenomes regarding the distribution of wellknown honey bee pathogens (members of the Iflaviridae family). The metagenomic data of the sample collected from apparently healthy colonies (Hajós) showed the absence of reads related to pathogens belonging to the Iflaviridae family. In contrast, the metagenome of the specimen that was sampled from decaying colonies (Visz) displayed 1,886 reads related to viruses of the Iflaviridae family, namely Deformed wing virus, Sacbrood virus and Varroa destructor virus (Fig. 1). According to the beekeeper, the latter group of honey bees was strongly infested by the parasitic mite Varroa destructor at the time of collection and showed signs of viral infections and nosemosis. Consequently, more than 200 of the beekeeper's 400 colonies were lost. According to our observations, we can confirm that the beekeeper's expertise greatly influences the health conditions of honey bees as has been described by Jacques et al. (2017). Especially, due to the horizontal and vertical transmission routes of certain honey bee pathogens (McMenamin et al., 2016), adequate beekeeping practices may greatly reduce the risk of infections. AmFV-specific PCR screening verified the presence of the virus in all examined 133 pools; however, the beekeepers had not noticed crawling bees at the entrance of hives at the time of collection, but during the homogenisation we noticed milky haemolymph in a few pools. It should be noted that the absence of signs does not definitely mean that this virus does not represent any danger to Western honey bees (Apis mellifera), since in the case of the Eastern 
hive honey bee (Apis cerana) the pathogenic potential of this virus has already been proved (Hou et al., 2016). In addition, a switch of a plant infecting virus (Tobacco ringspot virus, Secoviridae) from plants to honey bees has already been described (Li et al., 2014) which emphasises the importance of tracking inapparent viruses in the future.

To locate the phylogeographic origin of virus sequences identified in this study, a maximum-likelihood phylogenetic tree was constructed (Fig. 2). The tree shows that our sequences display two different geographic origins. Sequences of samples from Somberek (GenBank: MH431927) and Visz (GenBank: MH431926) are clustered together with European sequences creating a distinct European cluster and sharing 98\% identity with sequences from Switzerland. The other two sequences of this study [from Hajós (GenBank: MH431928) and Látrány (GenBank: MH431929)] segregated to a separate cluster with sequences from China, forming a distinct Asian cluster. Our phylogenetic tree well defines how the transport of honey bee colonies between foraging places, the international trade of bee and non-bee products or the exchange of queens between apiaries could contribute to the spread of different pathogens as suggested previously (Vanengelsdorp and Meixner, 2010; Jacques et al., 2017).

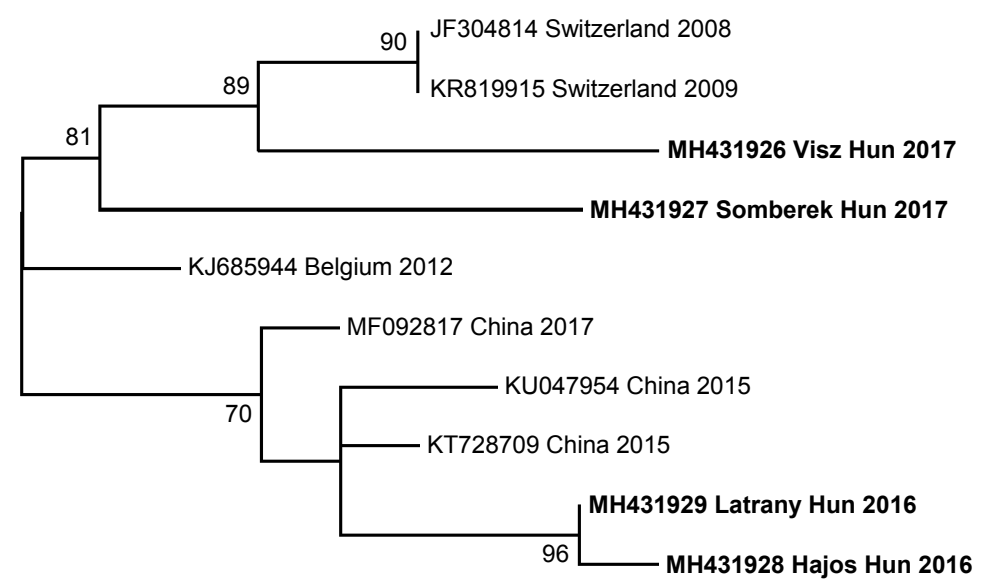

$$
\stackrel{\longmapsto}{0.002}
$$

Fig. 2. Phylogenetic tree of partial nucleotide sequences of the 460-bp-long BRO-B protein coding region of Apis mellifera filamentous virus (AmFV). The phylogenetic tree was constructed by Mega 7 program (Kumar et al., 2016) by using the maximum-likelihood method with Tamura-3 parameter model (T92) and 1000 replicates bootstrap value (only node values above $50 \%$ are shown). Sequences of the recent study are indicated in bold

Taken together, our findings suggest that AmFV infection can greatly affect the majority of individuals in a colony. Although there was no mortality 
linked specifically to this virus in the last decade (Hartmann et al., 2015), it still deserves attention and further investigations since very few data are available about its distribution to draw definitive conclusions.

\section{Acknowledgements}

The project was supported by the European Union, co-financed by the European Social Fund: Comprehensive Development for Implementing Smart Specialization Strategies at the University of Pécs (EFOP-3.6.1.- 16-2016-00004), and by the University of Pécs within the 'Viral Pathogenesis' Talent Centre programme. BZ was supported by the ÚNKP-18-3 New National Excellence Program of the Ministry of Human Capacities. The study was financed by the Higher Education Institutional Excellence Programme of the Ministry of Human Capacities in Hungary, within the framework of the 20765-3/ 2018/FEKUTSTRAT 'Innovation for Sustainable and Healthy Living and Environment' thematic programme of the University of Pécs.

\section{References}

Clark, T. B. (1978): A filamentous virus of the honey bee. J. Invertebr. Pathol. 32, 332-340.

Conceição-Neto, N., Zeller, M., Lefrère, H., De Bruyn, P., Beller, L., Deboutte, W., Yinda, C. K., Lavigne, R., Maes, P., Van Ranst, M., Heylen, E. and Matthijnssens, J. (2015): Modular approach to customise sample preparation procedures for viral metagenomics: a reproducible protocol for virome analysis. Sci. Rep. 5, 16532.

Gauthier, L., Cornman, S., Hartmann, U., Cousserans, F., Evans, J. D., de Miranda, J. R. and Neumann, P. (2015): The Apis mellifera filamentous virus genome. Viruses 7, 3798-3815.

Hartmann, U., Forsgren, E., Charrière, J. D., Neumann, P. and Gauthier, L. (2015): Dynamics of Apis mellifera filamentous virus (AmFV) infections in honey bees and relationships with other parasites. Viruses 7, 2654-2667.

Hou, C., Li, B., Luo, Y., Deng, S. and Diao, Q. (2016): First detection of Apis mellifera filamentous virus in Apis cerana cerana in China. J. Invertebr. Pathol. 138, 112-115.

Jacques, A., Laurent, M., EPILOBEE Consortium, Ribière-Chabert, M., Saussac, M., Bougeard, S., Budge, G. E., Hendrikx, P. and Chauzat, M. P. (2017): A pan-European epidemiological study reveals honey bee colony survival depends on beekeeper education and disease control. PLoS One 12, e0172591.

Kumar, S., Stecher, G. and Tamura, K. (2016): MEGA7: Molecular Evolutionary Genetics Analysis Version 7.0 for Bigger Datasets. Mol. Biol. Evol. 33, 1870-1874.

Li, J. L., Cornman, R. S., Evans, J. D., Pettis, J. S., Zhao, Y., Murphy, C., Peng, W. J., Wu, J., Hamilton, M., Boncristiani, H. F. Jr., Zhou, L., Hammond, J. and Chen, Y. P. (2014): Systemic spread and propagation of a plant-pathogenic virus in European honeybees, Apis mellifera. mBio 5, e00898-13.

Li, W., Cowley, A., Uludag, M., Gur, T., McWilliam, H., Squizzato, S., Park, Y. M., Buso, N. and Lopez, R. (2015): The EMBL-EBI bioinformatics web and programmatic tools framework. Nucleic Acids. Res. 43, W580-4.

McMenamin, A. J. and Genersch, E. (2015): Honey bee colony losses and associated viruses. Curr. Opin. Insect. Sci. 8, 121-129. 
McMenamin, A. J., Brutscher, L. M., Glenny, W. and Flenniken, M. L. (2016): Abiotic and biotic factors affecting the replication and pathogenicity of bee viruses. Curr. Opin. Insect. Sci. 16, 14-21.

National Research Council (NRC) (2007): Status of Pollinators in North America. Washington, DC: The National Academies Press. 37 pp.

Ravoet, J., De Smet, L., Meeus, I., Smagghe, G., Wenseleers, T. and de Graaf, D. C. (2014): Widespread occurrence of honey bee pathogens in solitary bees. J. Invertebr. Pathol. 122, 55-58.

Steinhauer, N. A., Rennich, K., Wilson, M. E., Caron, D. M., Lengerich, E. J., Pettis, J. S., Rose, R., Skinner, J. A., Tarpy, D. R., Wilkes, J. T. and Vanengelsdorp, D. (2014): A national survey of managed honey bee 2012-2013 annual colony losses in the USA: results from the Bee Informed Partnership. J. Apic. Res. 53, 1-18.

Vanengelsdorp, D. and Meixner, M. D. (2010): A historical review of managed honey bee populations in Europe and the United States and the factors that may affect them. J. Invertebr. Pathol. 103, S80-95.

This is an open-access article distributed under the terms of the Creative Commons Attribution 4.0 International License (https://creativecommons.org/licenses/by/4.0/), which permits unrestricted use, distribution, and reproduction in any medium, provided the original author and source are credited, a link to the CC License is provided, and changes - if any - are indicated. (SID_1) 